\title{
Investigation on Aircraft-store Compatibility Criteria of External Store Separation
}

\section{Wei Song ( $\nabla 15210987189 @ 126 . c o m)$}

People's Republic of China

\section{Research}

Keywords: safe separation criteria, external store, constant force assumption, Reynolds average N-S equation, unstructured dynamic overlap grid

Posted Date: May 19th, 2021

DOl: https://doi.org/10.21203/rs.3.rs-515674/v1

License: (c) (i) This work is licensed under a Creative Commons Attribution 4.0 International License. Read Full License 


\title{
Investigation on aircraft-store compatibility criteria of exter- nal store separation
}

\author{
Wei Song \\ China Academy of Aerospace Aerodynamics, 100074, Beijing, People’s Republic of \\ China
}

Email: 15210987189@126.com

\begin{abstract}
The evaluation of aircraft-store compatibility on external store separation is a key issue in the separation system of vehicle design. Firstly, the aircraft-store compatibility criterion of an external store separation is put forward, and then the criterion is converted to an unequal relationship between velocity and acceleration in vertical displacement and pitch angle based on the constant force assumption, which is validated by the test result of wing pylon finned store model (WPFS). The three-dimensional compressible Reynolds average N-S equation and rigid body six-degree-of-freedom motion equation (6-DOF) are solved by using unstructured dynamic overlap grid technology, to obtain the kinematic parameters of the external separation. Finally, the most dangerous point M on the tail of the external store is selected to verify the aircraft-store separation criterion. The results show that the kinematic parameters of the most dangerous point $\mathrm{M}$ on the tail wing of the store fall in the safe separation area, which means that the complete separated process is safe.
\end{abstract}

Keywords: safe separation criteria; external store; constant force assumption; Reynolds average N-S equation; unstructured dynamic overlap grid

\section{Introduction}

Reducing the launching cost of space load is an unremitting pursuit in the development of the transportation system between heaven and earth for many countries [1-2]. Reusable Launch Vehicle (RLV), as a transportation platform for space loads, has the remarkable characteristics of low cost, flexibility and conventional airport launch. RLV can be used not only as a low-earth orbit load transportation platform, but also as a combat weapon platform to carry out combat tasks such as precision strike and high-point reconnaissance, which is the key development direction of major aerospace countries [3-4]. The United States, Russia, Japan and many European countries have put forward various conceptual schemes around the Single Stage to Orbit (SSTO) [5] and Two Stage to Orbit (SSTO) [6] modes of RLV. The SSTO reusable launch vehicle scheme can separate the completed launch vehicle from the space load at an appropriate time and return to the ground, which reduces the consumption of engine propellant and decrease launch cost [7]. According to the state-of-the-art conditions, the reusable aircraft with two-stage orbit is more suitable for the round-trip transportation between heaven and earth [8].

The RLV system mainly consists of a first-stage carrier and a second-stage orbiter, in which the carrier is an aircraft that can return to the ground. The installation modes of the orbiter and carrier can be divided into external, internal, captive-on-top and towed [9-10]. The external reusable launch vehicle with wing or fuselage scheme has been relatively mature, which has been adopted by many countries in the world at present [11]. Two stage vehicles are usually still in the atmosphere when it is separated and the second-stage orbiter is usually separated from the carrier by ejection force and aerodynamic force [12]. There are serious aerodynamic interference problems such as shock wave/shock wave, shock wave/boundary layer and shock wave/vortex in the separation process between the orbiter and carrier, which will directly affect the aerodynamic characteristics of the orbiter. If the design of separation system is unreasonable, the collision between the orbiter and carrier may occur, which results in the failure of the carrier separation task [13].

A great deal of research has been done on the sep- 
aration and evaluation methods of separation systems of RLV at home and abroad. Wang [14] has carried out an experimental study on aerodynamic interference existing in the separation process of multi-body system of hypersonic vehicle. Wang found that there is a complex shock wave interference between booster and reentry vehicle in the separation process and it is concluded that the essence of aerodynamic interference is caused by shock wave interference. $\mathrm{Wu}$ [15] conducted a wind tunnel experiments on a typical reusable launch vehicle, accurately simulated the separation motion between two-stage aircraft and measured the aerodynamic characteristics of multi-body interference. Sickles [16] simulated the separation characteristics of an external aircraft by using structural overlap grid technology and three-dimensional unsteady numerical simulation method. He found that the initial separation velocity had a great influence on the trajectory of the separated objects. Snyder [17] solved the Euler equation and 6-DOF rigid body based on unstructured dynamic grid technology, and numerically simulated the separation motion of external airborne missile. The result is in good agreement compared with the wind tunnel results. The above studies have obtained the separation motion characteristics and aerodynamic characteristics of the separated store, but there is no uniform safety separation criterion. Wang [18] deduces the safety separation criterion according to the relative motion relationship between missile and carrier aircraft in the process of aircraft-missile separation, and uses the aerodynamic modeling method of free flow model and interference model to calculate the separation trajectory, which is used to evaluate the safety of aircraft-missile separation.

In this paper, the safety separation criterion of an external RLV is put forward, then the three dimensional compressible Reynolds average N-S equation and 6-DOF rigid body are solved by using unstructured dynamic overlap grid technology. Finally, the kinematic parameters are substituted into the safety separation criterion for verification.

\section{Criterion of aircraft-store compatibility for ex- ternal store separation}

\subsection{Separate reference coordinate system}

In order to evaluate and predict whether the external store can be safely and acceptably separated from the carrier-aircraft, it is necessary to establish a separation reference coordinate system and a store coordinate system that are fixedly connected with the store. The separation reference coordinate system is an inertial coordinate system, which is mainly used to describe the kinematic parameters (such as displacement, velocity and acceleration, etc.) of the store relative to the aircraft and the store coordinate system is mainly used to establish the motion equation. The separate reference coordinate system (red line) and the store coordinate system (blue line) are indicated in Fig. 1.

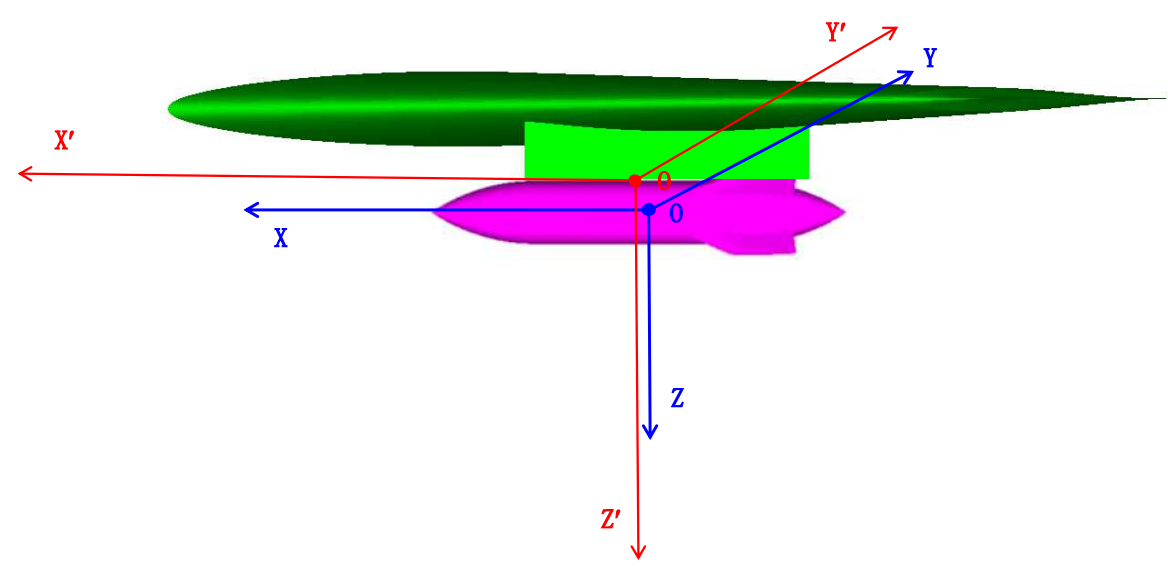

Fig. 1 Reference coordinate system

As shown in Fig. 1, the origin of the store coordinate system is located at the center-of-gravity (CG) of the store. The positive $\mathrm{X}$ is parallel to the central axis of store and opposite the direction of freestream. The 
positive $\mathrm{Z}$ is and the pointing head is positive. The positive $\mathrm{Y}$ is located in the longitudinal symmetry plane of the store and perpendicular to the $\mathrm{X}$-axis. The positive $\mathrm{Y}$ is given by right-hand system.

The separate reference coordinate system is a moving coordinate system connected to the carrier-aircraft and moves with the aircraft. The origin of the separate reference coordinate is a point on the upper surface of the aircraft, which is on the same line as the origin of the store coordinate system. For obvious difference, it is staggered in Fig. 1. At the initial time of the store separation, the three axes of the separation reference coordinate system and store coordinate system are parallel to each other.

\subsection{Criterion of compatibility for external store separation}

Rudy [19] pointed that the initial half second ( $t=0.5 \mathrm{~s})$ is the most important time for the trajectory and attitude angle analysis of store separating from the carrier-aircraft. During the initial time of $0.5 \mathrm{~s}$, the aerodynamic force and moment acting on the store are seriously affected by interference flowfield of the carrier-aircraft, which can make the trajectory and attitude-angle of store variable and uncertain. As indicated from Tomaro [20] that the external store must vertically fall down from 10 body-diameter, which can be considered as an safe separation event. In the motion of pitch direction, the absolute value of pitch angle cannot be greater than $9 \mathrm{deg}$ when the store reaches the 10 body-diameter long. Then, the criteria for evaluating the separation compatibility of external store in this paper can give as follows:

$$
Z \geq Z_{c}=2 \mathrm{~m} \quad t_{c}=0.5 \mathrm{~s}
$$

And

$$
|\theta| \leq\left|\theta_{c}\right|=9^{\circ} \quad t_{c}=0.5 \mathrm{~s}
$$

\subsection{Vertical displacement and pitch angle}

The vertical displacement $Z(t)$ and pitch angle $\theta(t)$ of the separated store are given as follows [21]:

$$
Z=Z_{0}+\Delta_{1} t+\Delta_{2} t^{2} / 2+\mathrm{L}
$$

And

$$
\theta=\theta_{0}+\nabla_{1} t+\nabla_{2} t^{2} / 2+\mathrm{L}
$$

Where $Z_{0}$ and $\theta_{0}$ are the vertical displacement and pitch angle at $t=0, \quad \Delta_{1}$ and $\Delta_{2}$ are the primary and secondary term of the vertical displacement for any point on the store. Similarly, $\nabla_{1}$ and $\nabla_{2}$ are primary and secondary term of the pitch angle.

Assumed that the motion trajectory of external store near the aircraft is mainly controlled by the aerodynamic force and gravity on the store at the initial release time. The aerodynamic force remains unchanged in a very short time (constant force assumption) and omits the higher-order term of time in formula (3), and then the formula (3) can be changed into a simple form:

$$
Z=\Delta_{1} t+\Delta_{2} t^{2} / 2
$$

Similarly, it is assumed that the attitude-angle of the external store separation near the aircraft is controlled by the aerodynamic moment on the missile at the initial release time, and remains unchanged in a very short time (constant moment assumption), and the formula (4) can be changed into the following form:

$$
\theta=\nabla_{1} t+\nabla_{2} t^{2} / 2
$$

Because of the assumption that the aerodynamic force and moment are constant in a short time, the $\Delta_{1}$ and $\Delta_{2}$ in equations (5) have a clear physical meaning. They are respectively vertical velocity $\&$ and acceleration (both relative to the aircraft) when the external store just leaves the ejection mechanism. Similarly, $\nabla_{1}$ and $\nabla_{2}$ are the pitch angular velocity $\theta_{0}^{\&}$ and angular acceleration at the initial time of separation.

By substituting formulas (5) and (6) into criterion (1) and (2), the criterion for evaluating the separation compatibility of external store is as follows:

$$
\Delta_{1} \geq \frac{Z_{c}}{t_{c}}-\frac{\Delta_{2} t_{c}}{2}
$$

And

$$
\left|\nabla_{1} t_{c}+\frac{\nabla_{2} t_{c}^{2}}{2}\right| \leq\left|\theta_{c}\right|
$$

The safety separation of external store is a sufficient condition for separation compatibility. Therefore, criterion (7) must meet at first. The safety separation area of external store after the introduction of criterion (7) is shown in Fig. 2. As seen from Fig. 2, the separation-region of vertical displacement for the external store can be divided into four regions (I IV). (1) For region I, the safety separation of external store has enough margin since the relative velocity $\Delta_{1}$ and acceleration $\Delta_{2}$ between external store and the aircraft are large at the time of initial separation. That is 
to say, when the relative velocity $\Delta_{1}$ and acceleration $\Delta_{2}$ of the store and aircraft fall in region I, the external store can safely separate from the interference flowfield of the aircraft. (2) For region II, when the relative velocity $\Delta_{1}$ is large enough but the relative acceleration $\Delta_{2}$ is small or even negative, as long as the relative velocity $\Delta_{1}$ is greater than $Z_{c} / t_{c}-\left(\Delta_{2}\right) t_{c} / 2$, the separation process of the external store can be considered as safe. (3) As seen in region III, although the relative velocity $\Delta_{1}$ and acceleration $\Delta_{2}$ between the external store and aircraft are both positive values, the separation process of the external store is not safe due to the small value and small safety margin, which does not meet the safety separation conditions. (4) Area IV is an unsafe separation region.

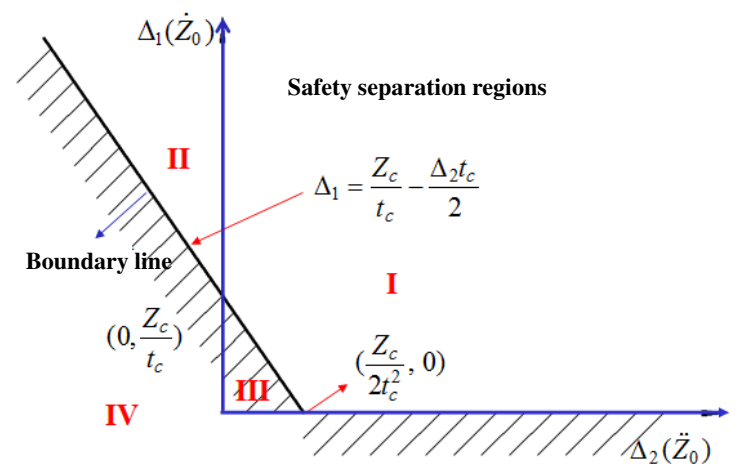

Fig. 2 Safety separation region in vertical direction

Fig. 3 shows the effective area of pitch angle $\theta$ of the external store by equation (8). As seen in Fig. 3 that the effective separation region can also be divided into four regions: (1) For the first-quadrant (A) and third-quadrant (B), the initial pitching-angular velocity $\nabla_{1}$ and acceleration $\nabla_{2}$ are in the same sign, which is a relatively dangerous area for the real store launch. Therefore, when the initial pitching-angular velocity $\nabla_{1}$ and acceleration $\nabla_{2}$ fall in the area of A and $\mathrm{B}$, there is a possibility of collision between the store and aircraft, which can be considered as incompatible. (2) The two regions of C and D are the regions of effective separation.

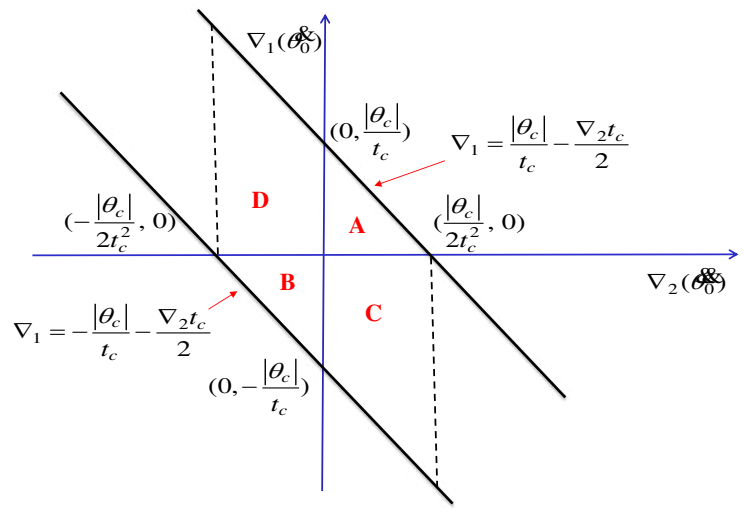

Fig. 3 Safety separation region in pitch direction

\section{Mathematical proof and verification of constant force assumption}

As seen in section 2.3 that the constant force and moment assumption are used to determine the aircraft-store compatibility of the external store separation. It is concerned about the errors of separation trajectory and attitude-angle of external store by using the constant force and moment assumption.

\subsection{Mathematical proof of constant force as- sumption}

The exact expression of vertical displacement $Z(t)$ can be written as follows:

$$
Z(t)=\frac{1}{m} \int_{0}^{t}\left[\int_{0}^{t} F(t) d t\right]
$$

Where $m$ is the mass of the store, $F(t)$ is the time-varying force acting on the store.

The time-varying force $F(t)$ can be make a Taylor series expansion at $t=0$ as follows:

$$
F(t)=F(0)+\sum_{n=1}^{\infty} F^{(n)}(0) \frac{t^{n}}{n !}
$$

Therefore, the expression of vertical-displacement is:

$$
\begin{aligned}
Z(t)= & \frac{1}{m}\left[\frac{F(0) t^{2}}{2 !}+\sum_{n=1}^{\infty} F^{(n)}(0) \frac{t^{n+2}}{(n+2) !}\right] \\
& +V_{0} t+Z_{0}, \quad t=0
\end{aligned}
$$

Here $V_{0}$ is the initial ejection-velocity of vertical direction, $Z_{0}$ is the vertical displacement at $t=0$.

It can be seen in equation (11) that the effect of variable force on vertical displacement is mainly reflected in the lower quadratic term of time since the separation time is very short. 


\subsection{Verification of constant force and moment assumption}

In order to verify the validity of constant force and moment assumption, the simplest way is to compare the real motion trajectory with that obtained by the constant force assumption. In this paper, a wing pylon finned store (WPFS) [22] is used to verify the constant force and moment assumption. The model is a general model issued by the Air Force Laboratory (AFL) to verify the compatibility of multi-body separation. The model has a wealth of wind tunnel captive trajectory system (CTS) test data, which is completed by AEDC Company. The geometric dimension of WPFS model is shown in Fig. 1. The wing in the combined-model is a trimming delta wing, which the wing section shape is the NACA64A010 airfoil. The leading and trailing edge sweep angle are $45^{\circ}$ and $0^{\circ}$. The aspect ratio of the wind is 1.73. The external store is a spiral body with four trimming delta wings. The airfoil of the wings on the store is NACA0008, with a leading edge sweep angle of $60^{\circ}$ and a trailing edge sweep angle of $0^{\circ}$. Two downward ejection forces are used in the initial-stage of separation to improve the separation of external store from the wing. The front ejection force is $10679.4 \mathrm{~N}$ and the distance between the action point and the head of the store is $1.24 \mathrm{~m}$. The rear ejection force is $42717.5 \mathrm{~N}$ and the distance between the action point and the head of the store is $1.75 \mathrm{~m}$. The acting length of ejection force is $0.1 \mathrm{~s}$ and the working time is about $0.05 \mathrm{~s}$.

Fig. 4 shows the comparison and error diagram between the simulation trajectory and the actual motion trajectory (wind tunnel CTS test data). Two normal force are applied in the simulation trajectory, respectively. That are the initial normal force $F_{N 0}$ at the time when two ejection forces disappear (defined as the initial time of $t=0$ ) and the average normal force $F_{N A}$ of the whole separation process. It can be seen from Fig. 4 (a) that the vertical displacement $Z$ obtained by using the initial and average normal force assumptions is almost coincident. The vertical-displacement obtained by the constant force assumption is smaller than the real motion trajectory. The simulation trajectories gained by initial and average normal force assumptions are very close to the actual trajectory, but the relative error is getting larger and larger as time goes on (as shown in Fig. 4(b)).
The relative error caused by the initial normal force assumption is larger than that of the initial average force assumption, but the maximum relative error is not more than $11 \%$, which is acceptable within a certain error range. Therefore, the constant force assumption in store separation is acceptable, which can give a rapid assessment of the safety of store separation.

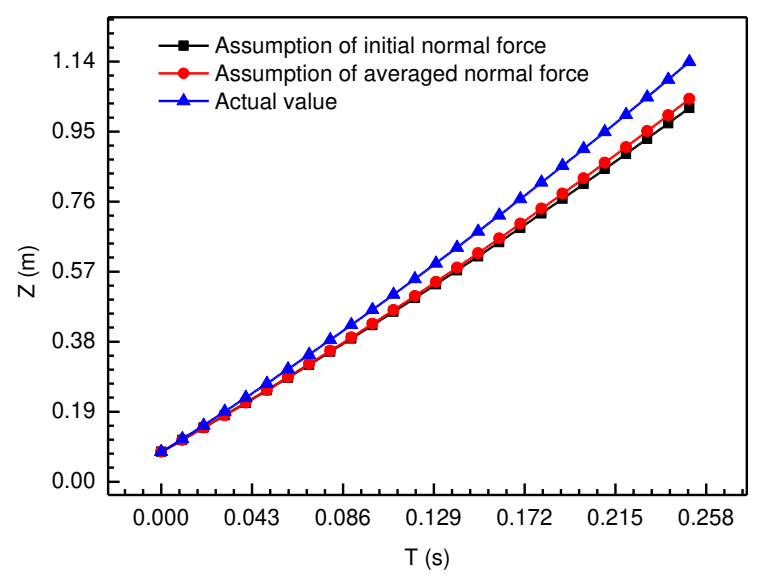

(a) Vertical displacement

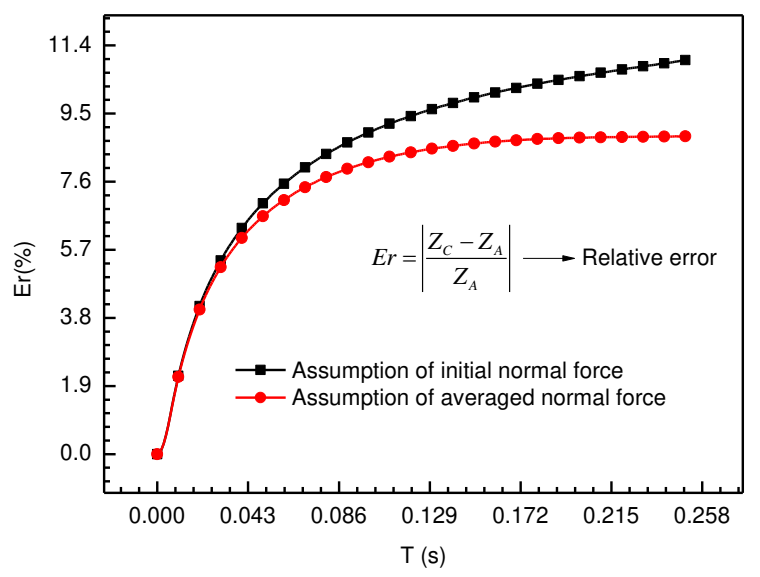

(b) Relative error

Fig. 4 Comparison of assumptive and actual value for vertical displacement

Fig. 5 shows the comparison and error diagram (all CTS test data) between the actual pitch-angle and the simulated pitch-angle using the initial pitch-moment as the constant moment. It can be seen from Fig. 5 (a) that it is effective to adopt the assumption of constant pitch-moment in the area of the aircraft flowfield. The flowfield near the aircraft has little influence on the pitch-moment of the store. However, as the store leaves the flowfield interference area of the aircraft, the simulated pitch-angle obtained by the constant moment assumption is larger than the real pitch-angle. 
The error is larger and larger as the time goes on, as seen in Fig. 5 (b). The result shows that the pitch-moment at the initial separation time cannot represent the effect of the flowfield in the interference area of the aircraft.

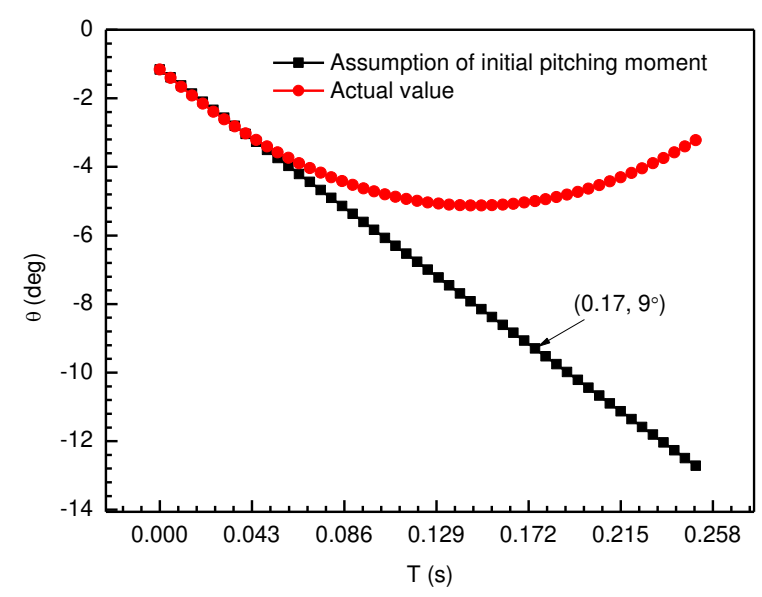

(a) Pitch angle

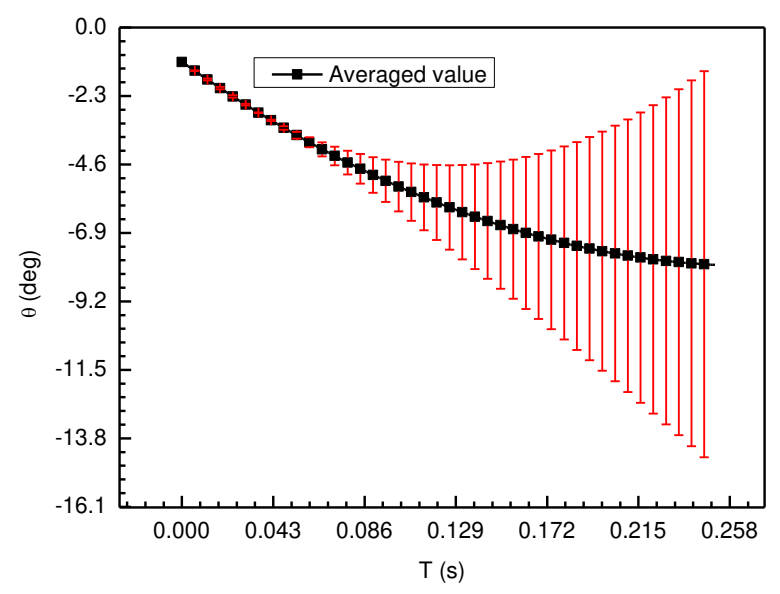

(b) Error

Fig. 5 Comparison of assumptive and actual value for pitch angle

\section{Numerical simulation method}

\subsection{Flow control equation}

The external store separation is a flow problem with moving boundary. The grid of store moves dynamically in the process of flow calculation. On the dynamic grid, the integral three-dimensional compressible Reynolds Average N-S equation is shown in Eq. (12) [23]:

$$
\frac{\partial}{\partial t} \int_{\Omega} \mathbf{W} d \Omega+\tilde{\mathbb{N}}_{\Omega}\left(\mathbf{F}_{c}-\mathbf{F}_{v}\right) d S=0
$$

where $\mathbf{W}$ is a conserved variable, $\mathbf{F}_{c}$ is in-viscid flux, $\mathbf{F}_{v}$ is viscous flux.

\subsection{Motion equation of six-degrees-of-freedom}

According to the theoretical mechanics, the motion of rigid-body can be divided into two kinds of motion: centroid translation and centroid rotation. The dynamic equations of centroid translation and rotation of store are given without deduction.

In inertial coordinate system, the translational dynamic equation of mass center of store is given by

$$
\left\{\begin{array}{l}
m \frac{d^{2} X_{C}^{\prime}}{d t^{2}}=F_{X} \\
m \frac{d^{2} Y_{C}^{\prime}}{d t^{2}}=F_{Y} \\
m \frac{d^{2} Z_{C}^{\prime}}{d t^{2}}=F_{Z}
\end{array}\right.
$$

Where $m$ is the mass of the store, $X_{C}^{\prime} 、 Y_{C}^{\prime} 、 Z_{C}^{\prime}$ is the CG displacement of the store, $F_{X} 、 F_{Y} 、 F_{Z}$ notes the three components of the resultant force vector of the store.

The dynamic equation of the CG rotation for rigid-body vehicle is given by Euler equation:

$$
\left\{\begin{array}{l}
I_{X} d \omega_{X} / d t+\omega_{Y} \omega_{Z}\left(I_{Z}-I_{Y}\right)=M_{X} \\
I_{Y} d \omega_{Y} / d t+\omega_{X} \omega_{Z}\left(I_{X}-I_{Z}\right)=M_{Y} \\
I_{Z} d \omega_{Z} / d t+\omega_{Y} \omega_{X}\left(I_{Y}-I_{X}\right)=M_{Z}
\end{array}\right.
$$

Where $M_{X} 、 M_{Y} 、 M_{Z}$ mean three components of combined force moment vector $\mathbf{M}$ of rigid-body in store coordinate system, $\omega_{X} 、 \omega_{Y} 、 \omega_{Z}$ are three components of angular velocity $\omega$ of rigid-body in store coordinate system, and $I_{X} 、 I_{Y} 、 I_{Z}$ are principal moment of inertia for rigid-body.

\subsection{Dynamic unstructured overlapping grid}

In the process of dynamic separation of aircraft-store, there is relative motion among multiple bodies, which need dynamic grid technology to simulate the dynamic separation motion among multiple bodies. Unstructured overlapping grid technology combines the characteristics of unstructured grid adapting to complex shape and overlapping grid dealing with large relative motion, which not only reduces the difficulty of grid generation for complex shape, but also improves the ability of dealing with large relative motion. Therefore, this paper adopts dynamic unstructured overlapping grid method technology.

Specific steps of dynamic unstructured dynamic 
grid algorithm:

(1) first carry out grid division on aircraft and store respectively, overlapping and nesting the carrier flow field grid and the orbiter flow field grid, determining the nesting relationship of overlapping boundaries, and realizing the information transmission between the flow fields of two computational domains;

(2) Input initial and boundary conditions to solve the steady flow field of the aircraft and store as the initial value for solving the unsteady flow field;

(a) Circulate the grids and calculate the flow parameters on moving nodes;

(b) Break down the flow field calculation if it reaches the required precision, otherwise, returning to step (a);

(3) Calculate the resultant force $\mathbf{F}$ and moment $\mathbf{M}$ on the orbiter at the time of $t$

(4) Solve the six-degree-of-freedom motion equation of rigid-body and obtain the position and attitude information of the store at the time of $t+\Delta t$. Then update the computational grid to a new position and redetermine the overlapping relationship of the computational domain grid.

(5) Judge whether the required state reach the required precision, and if so, end the calculation; otherwise, return to step (1).

\subsection{Computational grids and conditions}

Fig. 6 shows the schematic diagram of the overlap between the aircraft (wing) grid and the store grid at the initial time.

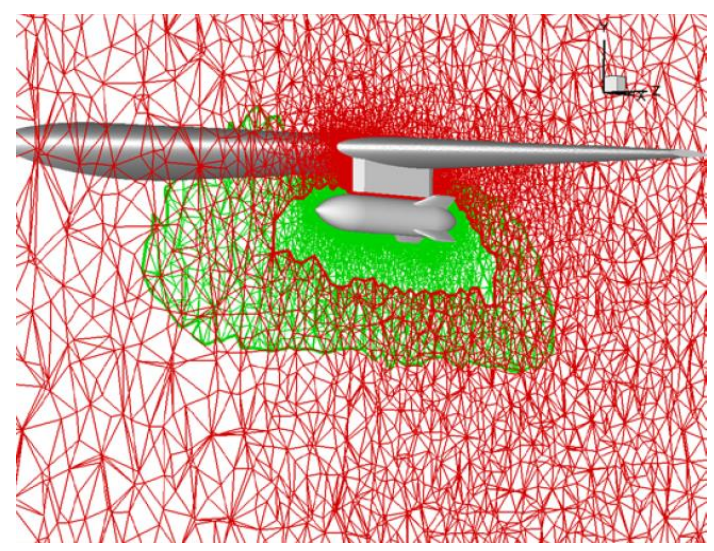

Fig. 6 Overset grid for vehicle in initial moments

Table 1 shows the calculation parameters.

Table 1 Parameter for numerical simulation

\begin{tabular}{ll}
\hline Calculation parameters & value \\
\hline Mach number & 0.95
\end{tabular}

$\begin{array}{ll}\text { Flight height / m } & 8000 \\ \text { Angle of attack / }^{\circ} & 1 \\ \text { Center of gravity / m } & 1.417 \\ \text { Mass / kg } & 906.87 \\ \text { Rolling moment of inertia / } \mathrm{kg} \cdot \mathrm{m}^{2} & 27.12 \\ \text { Pitch moment of inertia / } \mathrm{kg} \cdot \mathrm{m}^{2} & 488.1 \\ \text { Yaw moment of inertia / } \mathrm{kg} \cdot \mathrm{m}^{2} & 488.1\end{array}$

The separation of store is divided into two stages: (1) the stage of ejection force acting on the store (stage A), in which the store is acted by ejection force, aerodynamic force and self-gravity; (2) The stage of free flight (stage B), in which the store is acted by self-gravity and aerodynamic force.

\section{Numerical calculation results and verification of safety separation evaluation}

\subsection{Numerical calculation results}

Fig. 7 indicates the time-history of linear displacement, linear velocity, angular displacement and velocity of separated store. It can be seen from Fig. 7 (a) that no matter in stage A or stage B, the store always moves downward of the wing and its amplitude is the largest one compared with the other two directions. For stage A, the vertical speed of the store increases rapidly in a short time (about $0.06 \mathrm{~s}$ ) and changes slowly after the two ejection forces acting on the store disappearing, as shown in Fig. 7 .

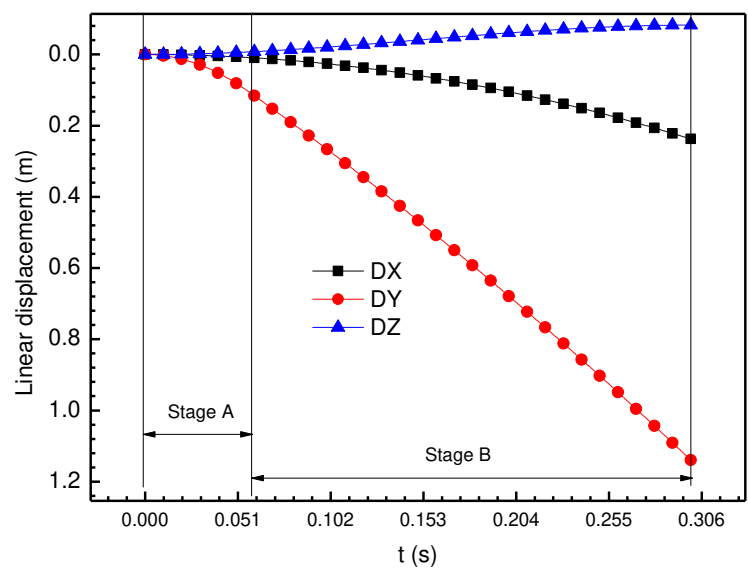

(a) Linear displacement 


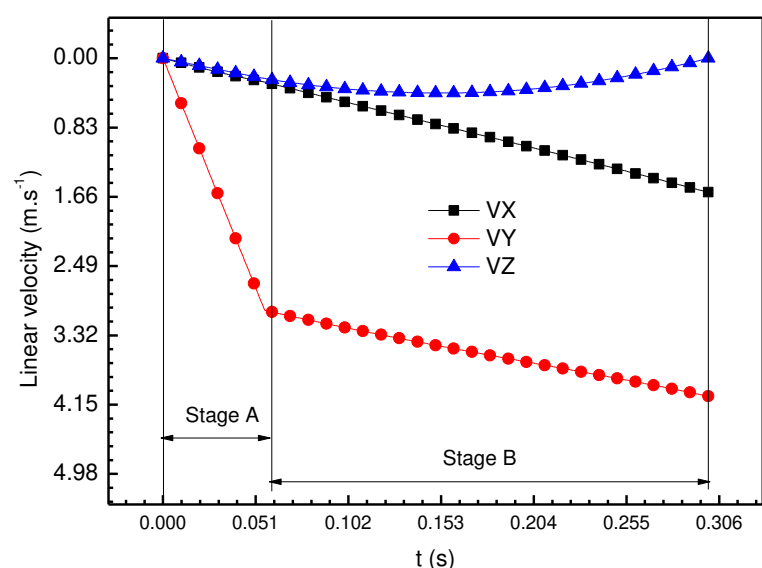

(b) Linear velocity

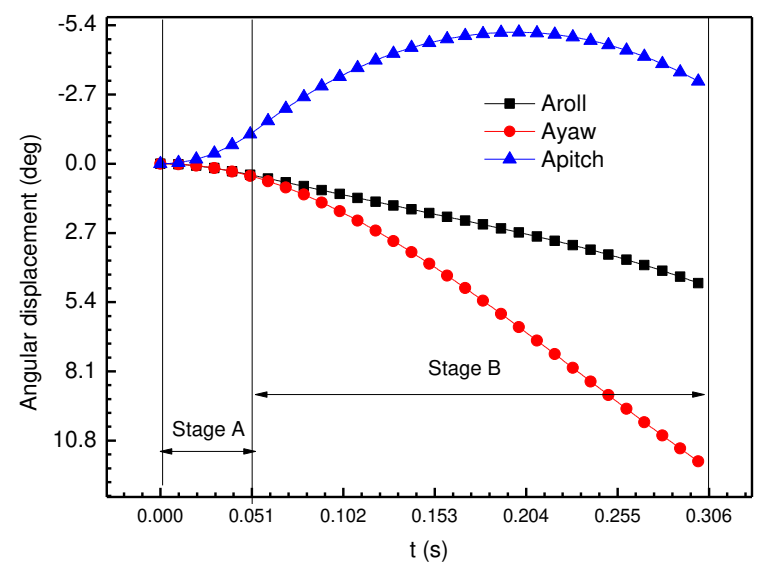

(c) Angular displacement

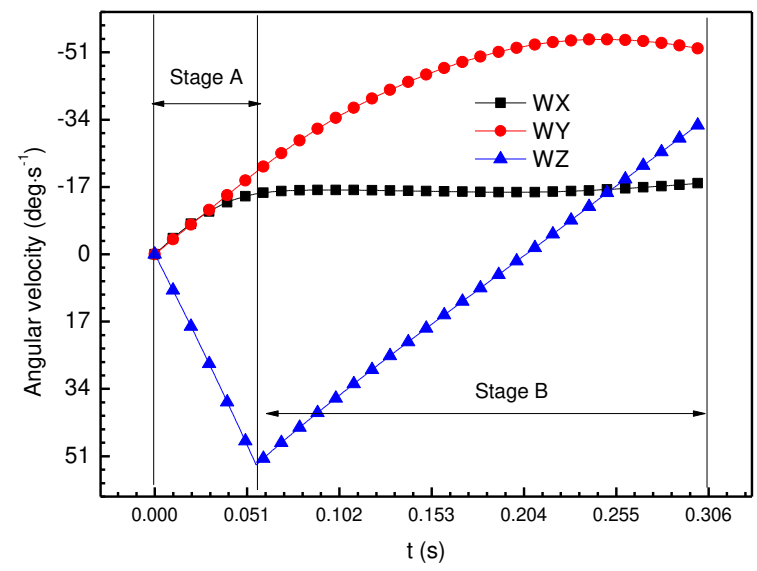

(d) Angular velocity

Fig. 7 History of linear displacement, linear velocity, angular displacement, angular velocity for external vehicle

It can be seen from Fig. 7 (c) that the external store appears nose-up pitch angle in stage $\mathrm{A}$, which is mainly because the nose-up pitching moment produced by the rear ejection force is greater than the nose-down pitching moment produced by the front ejection force. In stage A, although the nose of the store move upward, the head of the store will not col- lide with the carrier-wing and the separation of the external store is safe at this stage. In stage B, the store appears nose-down pitch angle, which indicates that the pitching moment of aerodynamic force on the store is negative. The maximum value of pitch angle requires the in inequality (2), as shown in Fig. 7 (c). As the store moves downward in vertical direction, the four tailing wings are the most likely parts to collide with the wing since the tails of store will raise up. It can be seen from Fig. 7 (d) that the rolling angular velocity of the store in stage $\mathrm{B}$ hardly changes. Therefore, the point $\mathrm{M}$ on the tail when the ejection force disappears is selected as the characteristic point. If the point $\mathrm{M}$ does not collide with the wing, the whole rigid-body will not collide with the wing.

\subsection{Safety separation assessment verification}

$\Delta_{1}$ and $\Delta_{2}$ are is relative velocity and acceleration. Now, we need to give the value of $\Delta_{1}^{M}$ and $\Delta_{2}^{M}$.

The store can be seen a free rigid-body. According to the velocity composition theorem, we know that the velocity of any point $M$ in the free rigid body [24]:

$$
\begin{aligned}
& \stackrel{1}{V_{M}}=\stackrel{1}{V_{C}}+\stackrel{r}{\omega} \times \stackrel{r}{r}
\end{aligned}
$$

Where $\stackrel{\mathrm{I}}{V_{C}}$ is the centroid velocity, $\stackrel{1}{\omega}$ is the instantaneous angular velocity rotating around the centroid, and $\stackrel{I}{r}$ is the vector diameter of the point relative to the centroid.

The acceleration of any point $m$ in the rigid body is [24]:

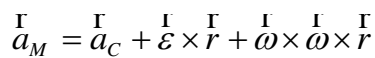

Where $\stackrel{I_{C}}{a}$ is the acceleration of the CG, $\stackrel{1}{\varepsilon}$ is the instantaneous angular acceleration when the rigid body rotates around the centroid.

Substituting the motion parameters of the center-of-gravity in numerical calculation into the formula (15) and (16), the time-varying relationship of $\Delta_{1}^{M}$ and $\Delta_{2}^{M}$ can be obtained, as shown in Fig. 8 . 


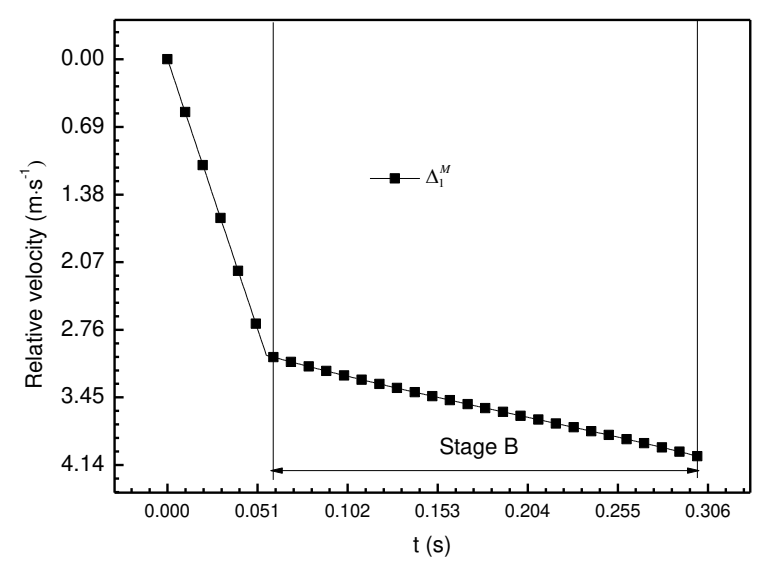

(a) Relative velocity

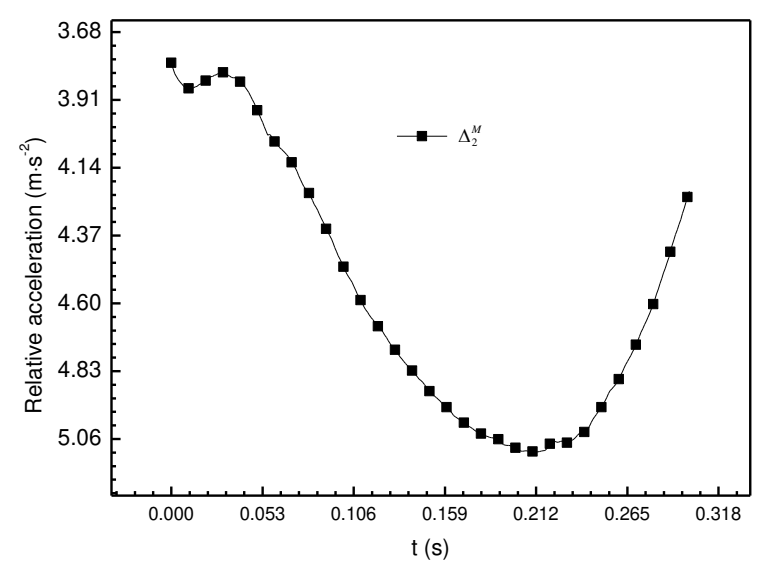

(b) Relative acceleration

Fig. 8 History of relative velocity, relative acceleration of point $\mathrm{M}$

It can be seen from Fig. 8 that the minimum values of relative velocity and acceleration of point $\mathrm{M}$ occur when ejection force disappears. If the minimum values of relative velocity and relative acceleration can fall in area A or B in Fig. 2, the store can be safely separated from the carrier with a certain safety margin. Fig. 9 is the falling point diagram of the safe separation area of the most dangerous point $\mathrm{M}$ and it can be seen that the point $M$ falls in area $A$, which means that the separation movement of the rigid body is safe.

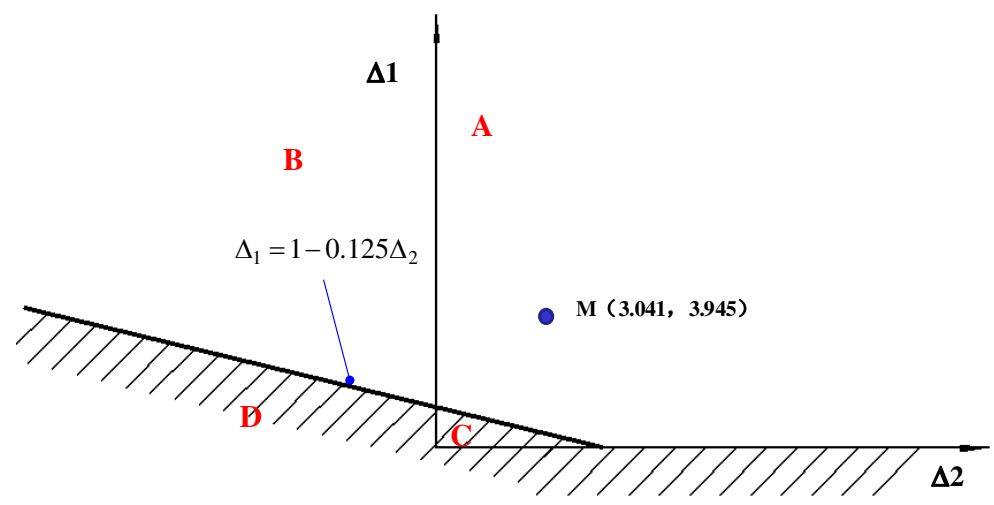

Fig. 9 Schematic diagram of safe separation area for point $M$

\section{Conclusion}

The safety evaluation of store separation is a key technical problem in the separation system of aircraft. Firstly, the safety separation criterion of an external store is derived and the relationship between the velocity and acceleration of the external store relative to the carrier is established. Then, the three-dimensional compressible Reynolds Average N-S equation and rigid body six-degree-of-freedom motion equation are coupled and solved by using unstructured dynamic overlapping grid technology, and the kinematic parameters of the $\mathrm{CG}$ of the external store are obtained. The most dangerous point $\mathrm{M}$ on the tail of the external store is selected to verify the separation criterion and the kinematic parameters of the point $\mathrm{M}$ can fall in the safe separation area, which shows that the whole separation process of the external store is safe. This safety separation criterion can be used not only for safety separation evaluation of external store, but 
also for the separation evaluation of captive-on-top and internal store embedded orbiters.

\section{References}

1. Deneu, F., Malassigne, M., Le-Couls, O., et al.: Promising solutions for fully reusable two-stage-to-orbit configurations. Acta Astronautica 56(8), 729-736 (2005)

2. Bradford, J.E., Charania, A., Wallace, J., et al.: Quick-sat: a two-stage-to orbit reusable launch vehicle utilizing air-breathing propulsion for responsive space access. AIAA 2004-5950.

3. Fujii, K., Ishimoto, S.: Research activities to realize advanced space transportation system. AIAA 2008-2575.

4. Ishimoto, S., Mori, T.: Study on a two-stage partially reusable launch vehicle as a reference system. The 48th Space Science and Technology Conference Japan, 656-661 (2011).

5. Yoshida, H., Micci, M.M., Nakane, M., et al.: Integrated optimization for single-stage-to-orbit using a pulse detonation engine. Journal of Spacecraft and Rockets 56(4), 983-989 (2019)

6. Dissel, A.F., Kothari, A.P., Lewis, M.J.: Investigation of two-stage-to-orbit air breathing launch-vehicle configurations. Journal of Spacecraft and Rockets 43(3), 568-576 (2006)

7. Liu, L., Yang, X.F., Xiao, G.M., et al.: Weight and size estimation method of two stage to orbit reusable launch vehicle. Acta Aerodynamica Sinica 36(6), 927-933 (2018)

8. Zhang, G.C., Yao, Y.L., Wang, H.: A survey on development of two stage to orbit horizontal takeoff horizontal landing reusable launch vehicle in USA. Aircraft Design 38(2), 1-6 (2018)

9. Marti, S.K., Nesrin, S.K.: Trade studies for air launching a small launch vehicle from a cargo aircraft. In 43rd AIAA Aerospace Sciences Meeting and Exhibit, Reno, Nevada (2005).

10. Masashi, M.: State estimation and quick trajectory optimization for air-launch rocket. IFAC Proceedings Volumes 43(15), 148-153 (2010)

11. Yang, L.: Numerical simulation of weapon separation based on unstructured overset grid and CFD/6DOF method. Nanjing University of Aeronautics and Astronautics, Nan Jing (2014)

12. Ruan, J.G., He, G.Q., Lu, X.: Trajectory optimization method in two stage to orbit RBCC RKT launch vehicle. Acta Aeronautica et Astronautica Sinica 35(5), 1284-1291 (2014)

13. Jiang, H.J., Yang, C.: Numerical simulation of hypersonic aerodynamic interactions around two stage to orbit vehicles. Physics of Gases Theory and Applications 3(2), 149-143 (2008)

14. Wang, Y.J., Wu, J.F., Tao, Y., et al.: Hypersonic experimental investigation on interference and stage separation of a multi-body system. Journal of Aerospace Power 25(4), 2-6 (2010)

15. Wu, J.F., Wang, Y.J., Luo, X.F., et al.: A test technique for multi-body interference and separation in hypersonic wind tunnel. Journal of Experiments in Fluid Mechanics 24(3), 99-102 (2010)

16. Sickles, W.L., Power, G.D., Calahan, J.A., et al.: Application of a CFD moving-body system to multi-component store separation. AIAA 2007-4073

17. Snyder, D.O., Koutsavdis, E.K., Anttonen, J.S.R.: Transonic store separation using unstructured CFD with dynamic meshing. AIAA 2003-3919.

18. Wang, H.Z., Li, X., Wang, X.P., et al.: Safety assessment for store separation. Aerospace Shanghai 34(5), 124-129 (2017)

19. Rudy, A.J., Michael, J.S., James, E.G.: Store separation trajectory deviations due to unsteady store bay aerodynamics. AIAA-2008-0188, 2008

20. Tomaro, R.F., Witzeman, F.C., Strang, W.Z.: A solution on the F-18C for store separation simulation using Cobalt60. AIAA 99-0122

21. Covert, E.E.: Definition of safe-separation criteria for external stores and pilot escape. AD726695, NWC TP 4995

22. Heim, E.: CFD wing/pylon/finned store mutual interference wind tunnel experiment. AEDC-TSR-91-P4, 1991

23. Tian, S.L., Investigation of overset unstructured grids algorithm. Nanjing University of Aeronautics and Astronautics, Nan Jing (2008)

24. Wang, Y.: Theoretical mechanics. (Seventh edn.) Higher education press, Bei Jing (2009) 


\section{Declarations}

7 Availability of data and materials

The author declare that all the data and materials are valid

\section{Competing interests}

The author declares that they have no known competing financial interests or personal relationships that could have appeared to influence the work reported in this paper.

\section{Funding}

The paper is the result of free research and has not been supported by various fundings

\section{Authors' contributions}

There is only one author in the paper, and there is no contribution from other authors

\section{Acknowledgements}

Not applicable

\section{Authors' information (optional)}

Name: Wei Song

Research Field: Multibody aerodynamics, Multibody separation dynamics, Flow control. Address: No.17 Yungang West Road, Fengtai District, Beijing

Email: 15210987189 
Figures

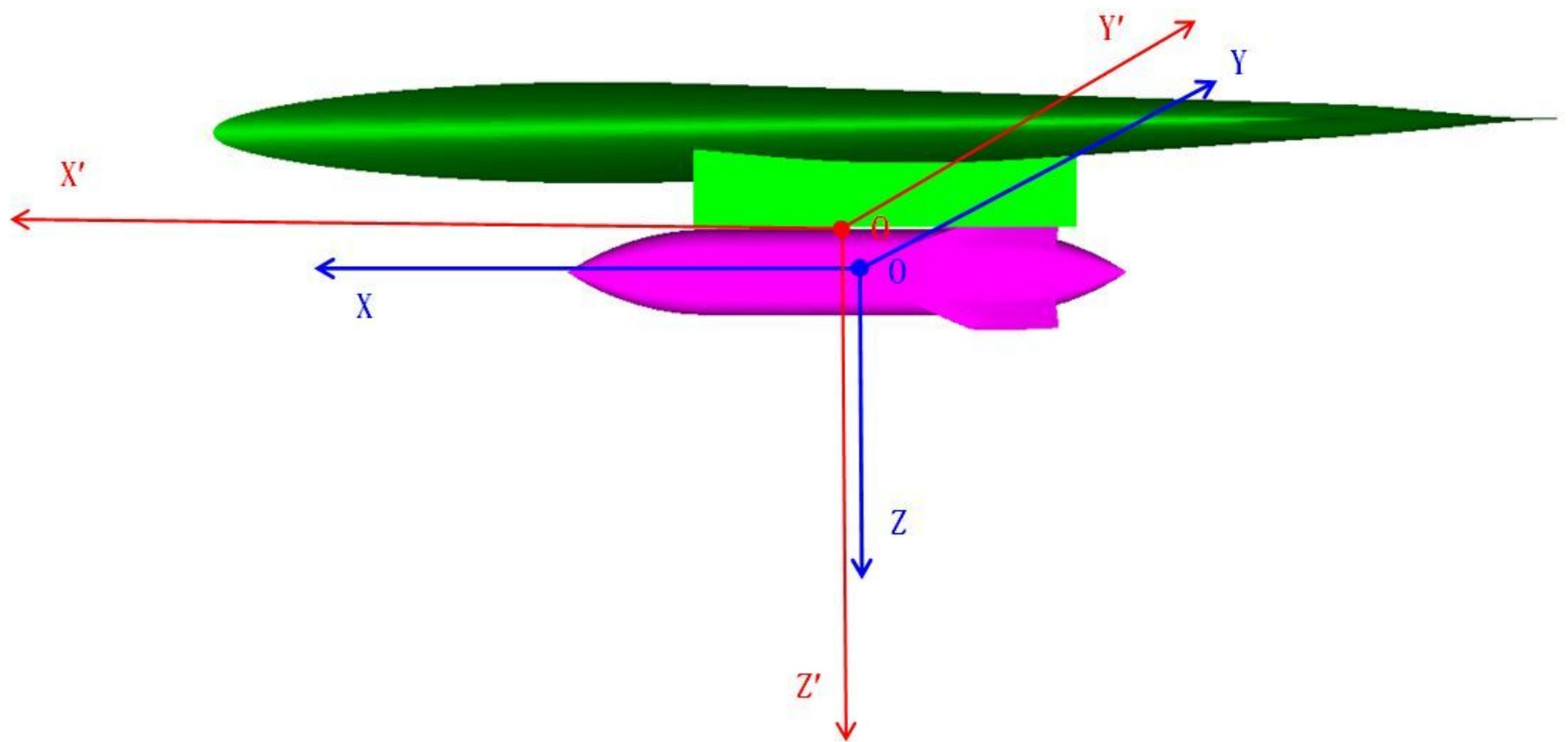

Figure 1

Reference coordinate system 


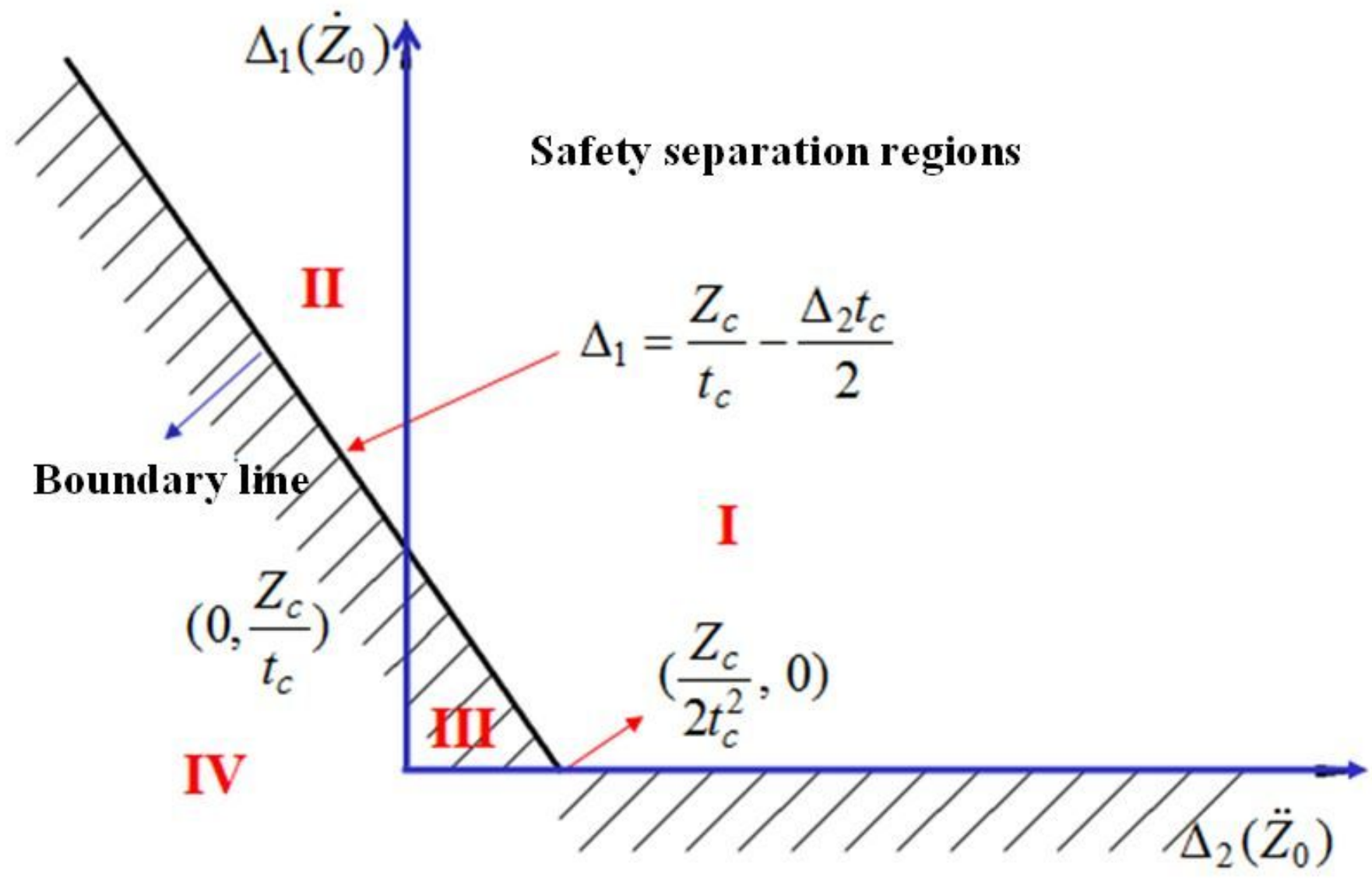

Figure 2

Safety separation region in vertical direction 


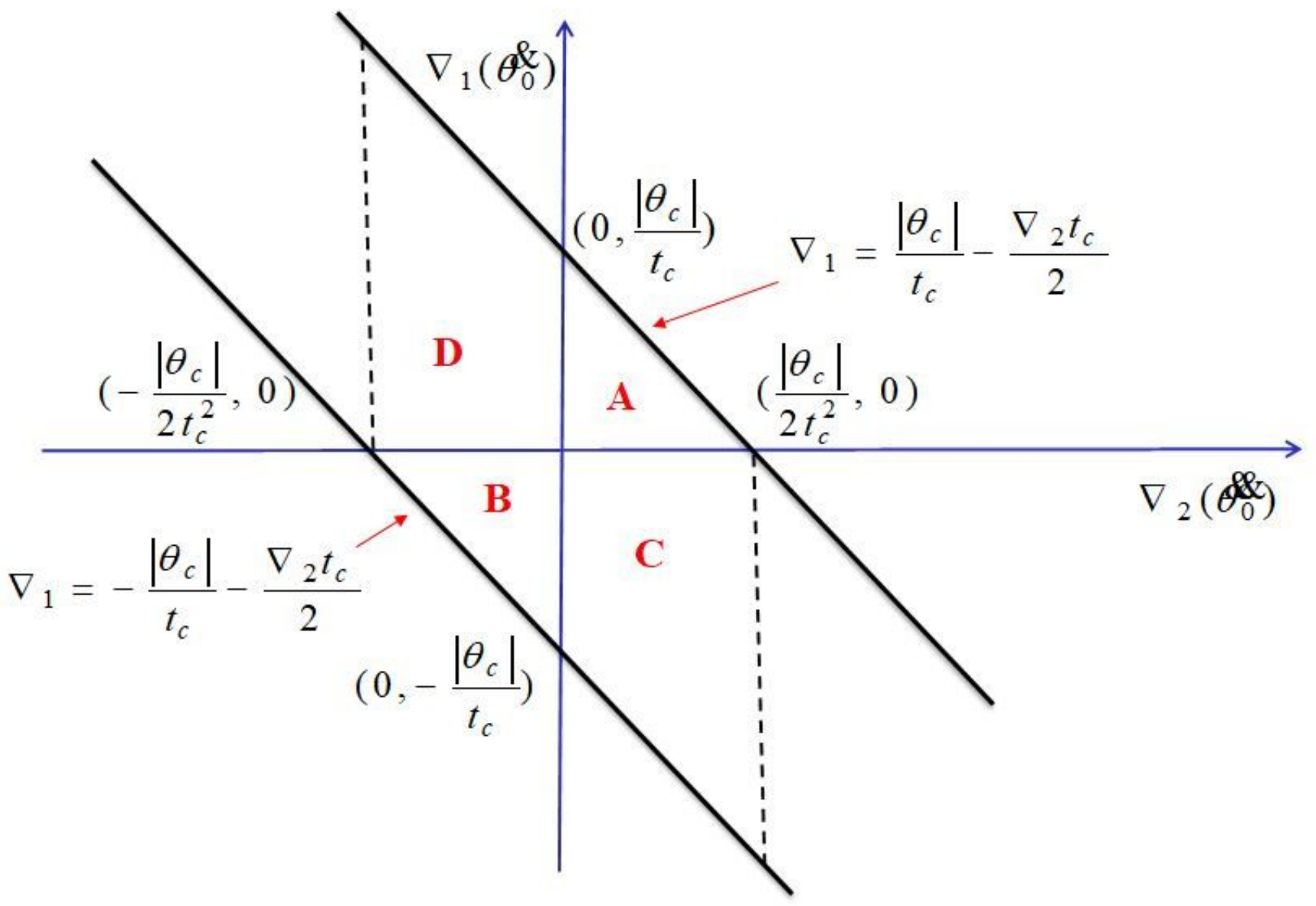

Figure 3

Safety separation region in pitch direction 


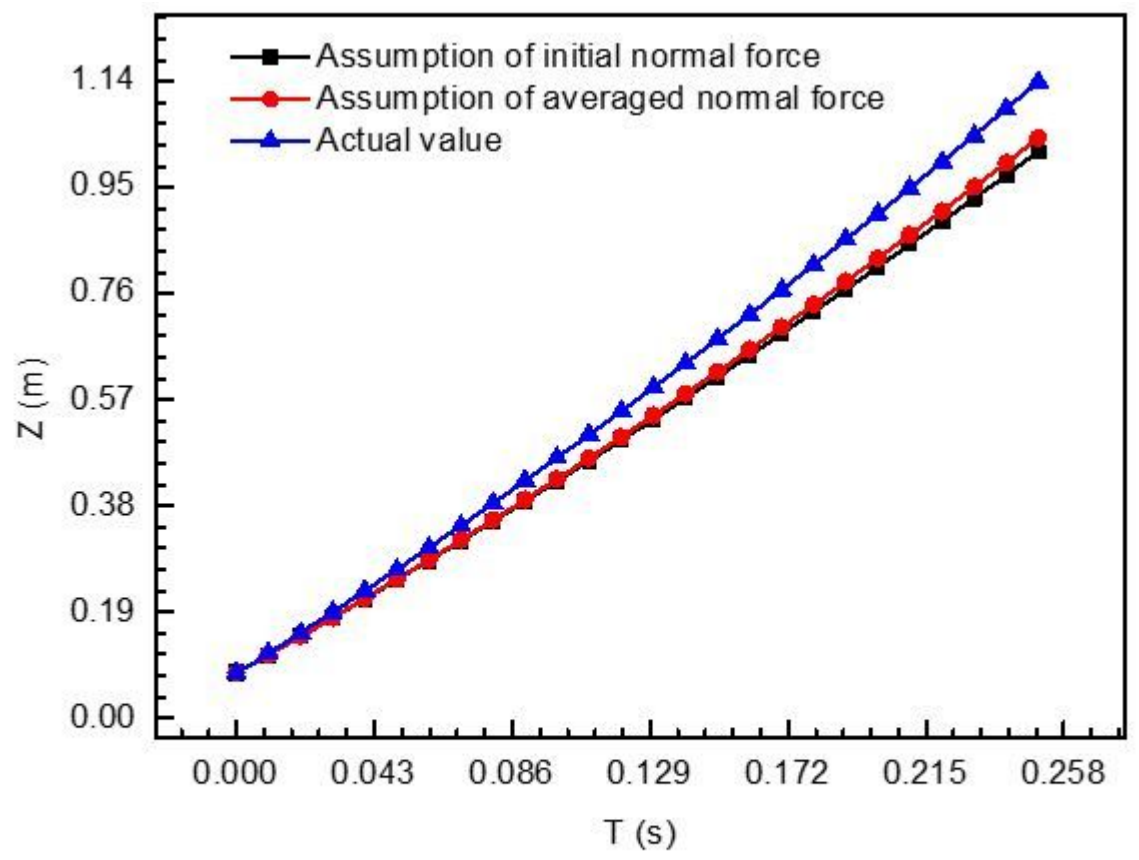

(a) Vertical displacement

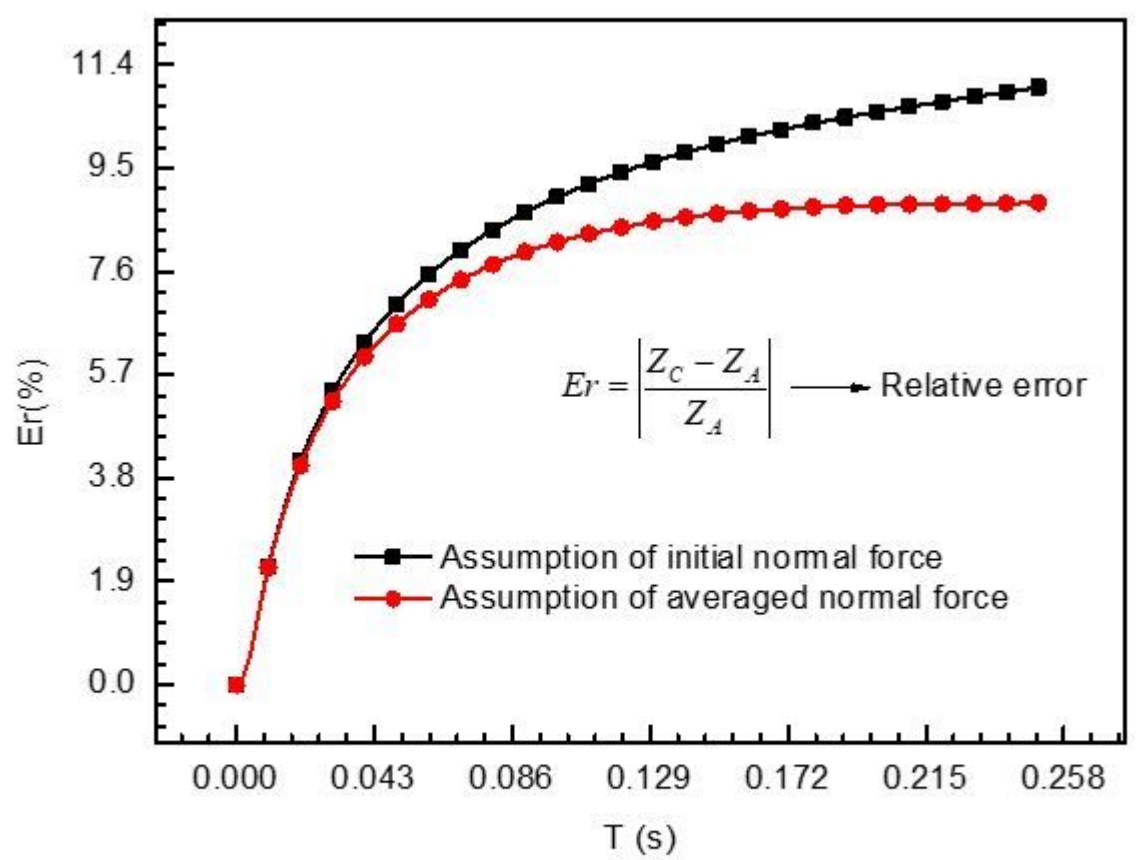

(b) Relative error

Figure 4

Comparison of assumptive and actual value for vertical displacement 


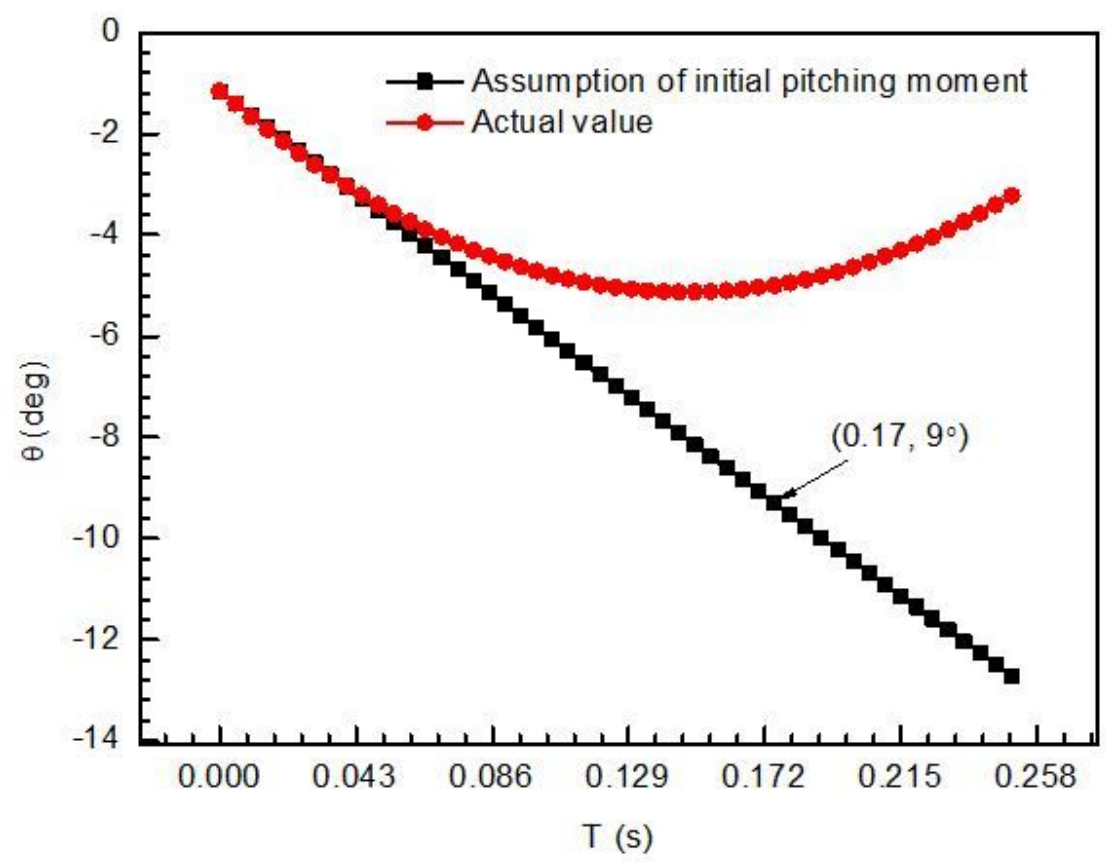

(a) Pitch angle

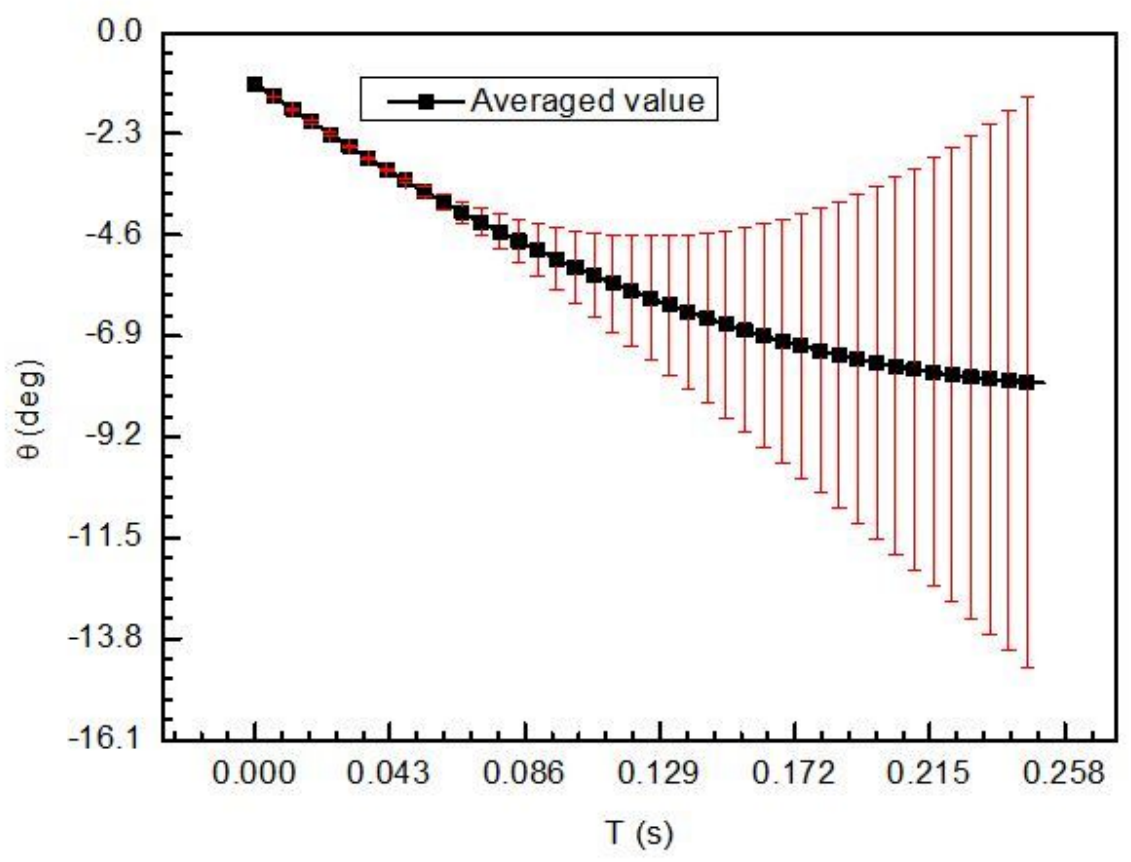

(b) Error

Figure 5

Comparison of assumptive and actual value for pitch angle 


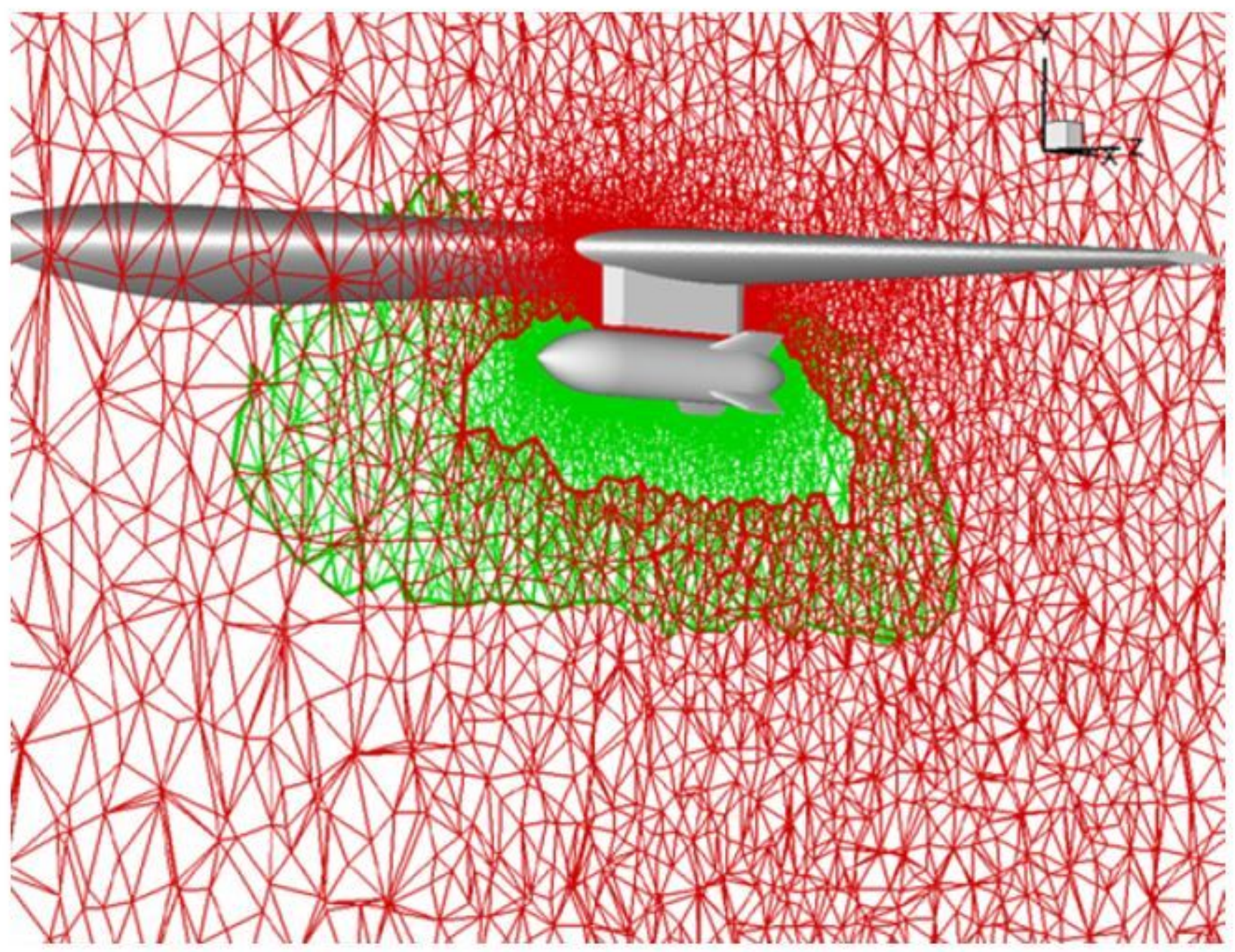

Figure 6

Overset grid for vehicle in initial moments 


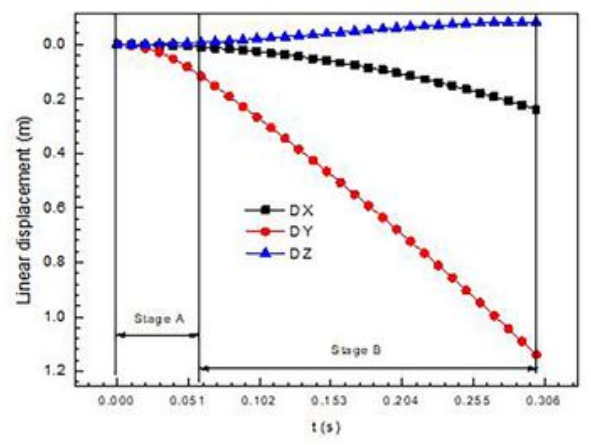

(a) Linear displacement

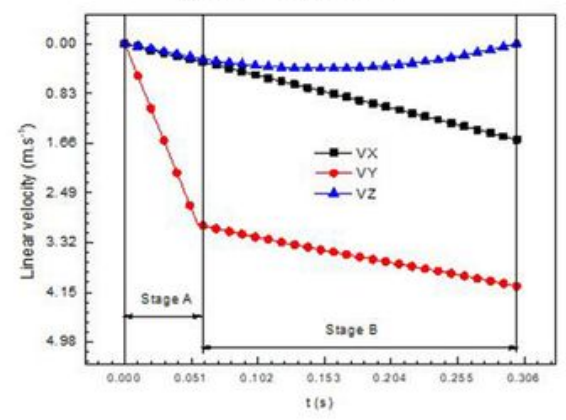

(b) Linear velocity

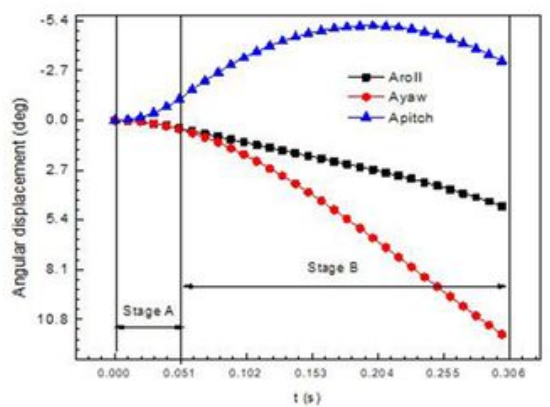

(c) Angular displacement

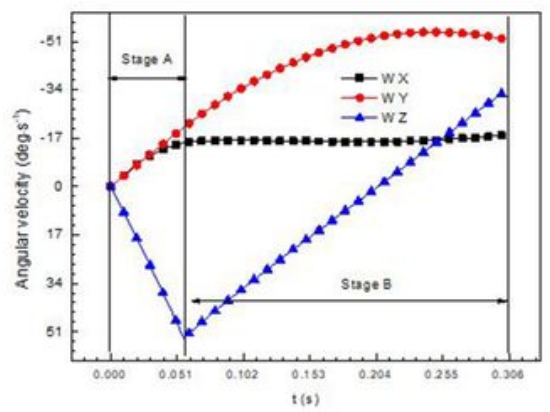

(d) Angular velocity

\section{Figure 7}

History of linear displacement, linear velocity, angular displacement, angular velocity for external vehicle 


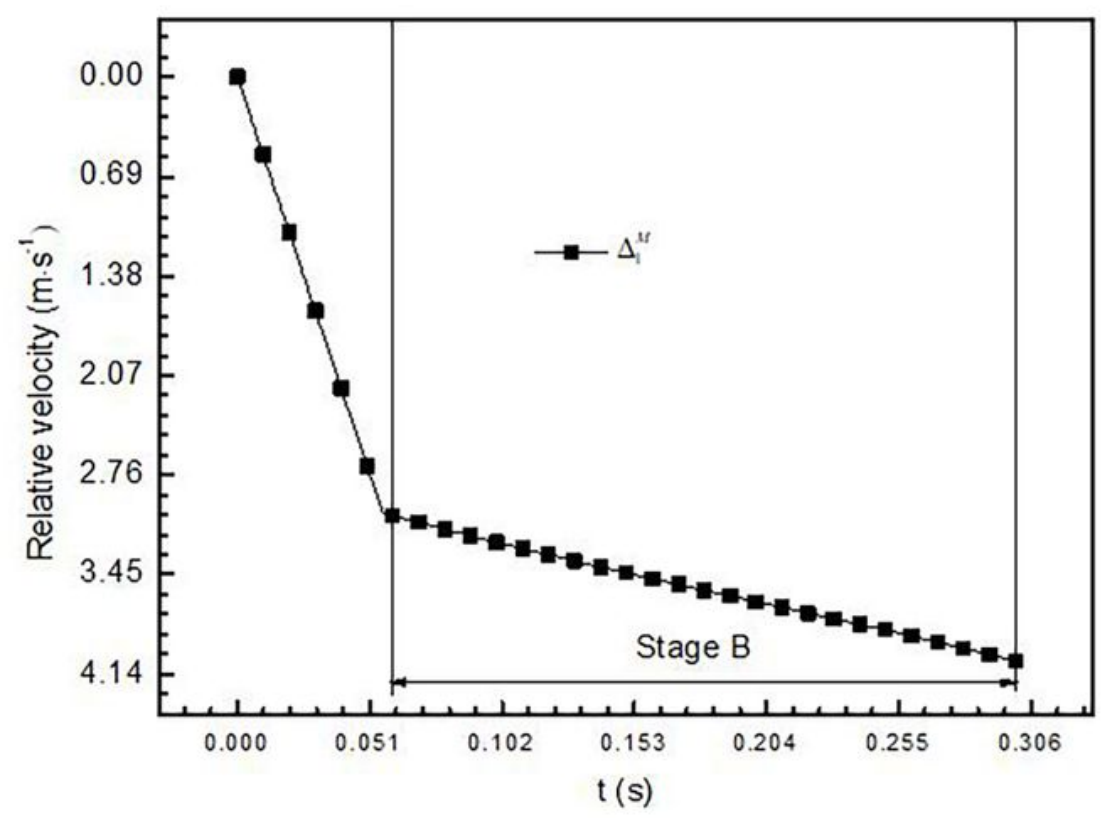

(a) Relative velocity

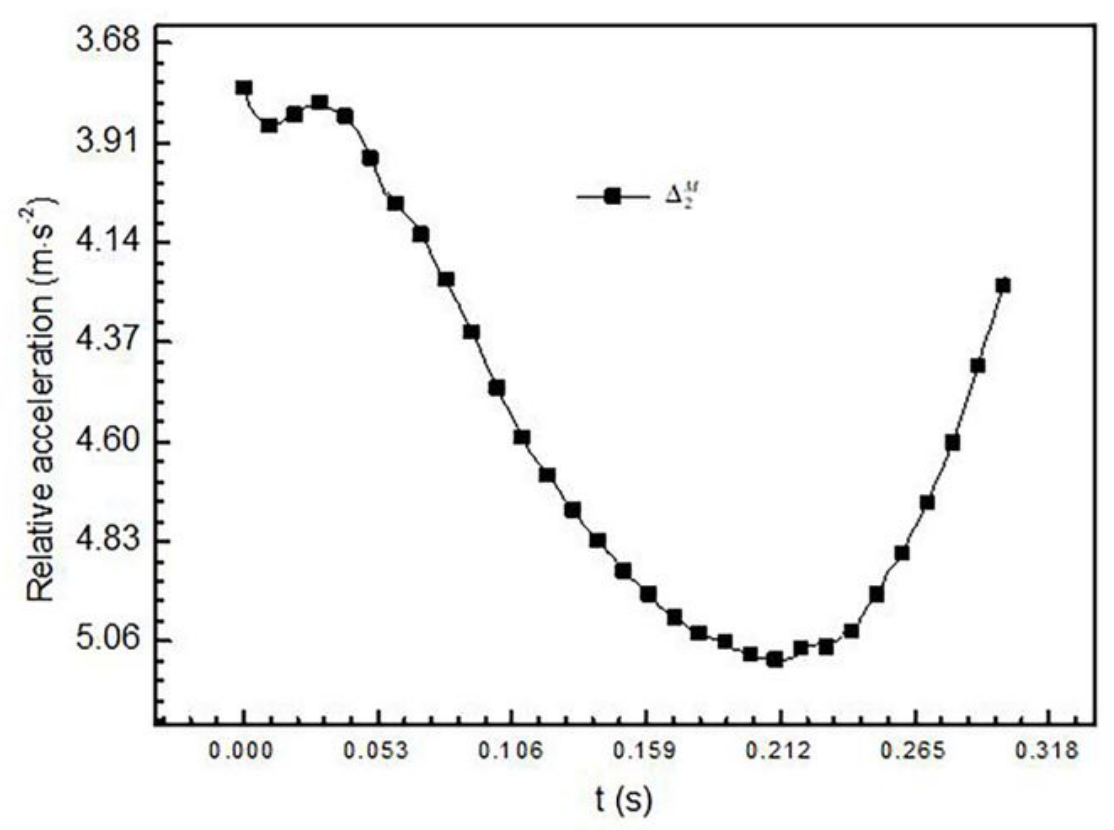

(b) Relative acceleration

\section{Figure 8}

History of relative velocity, relative acceleration of point $M$ 


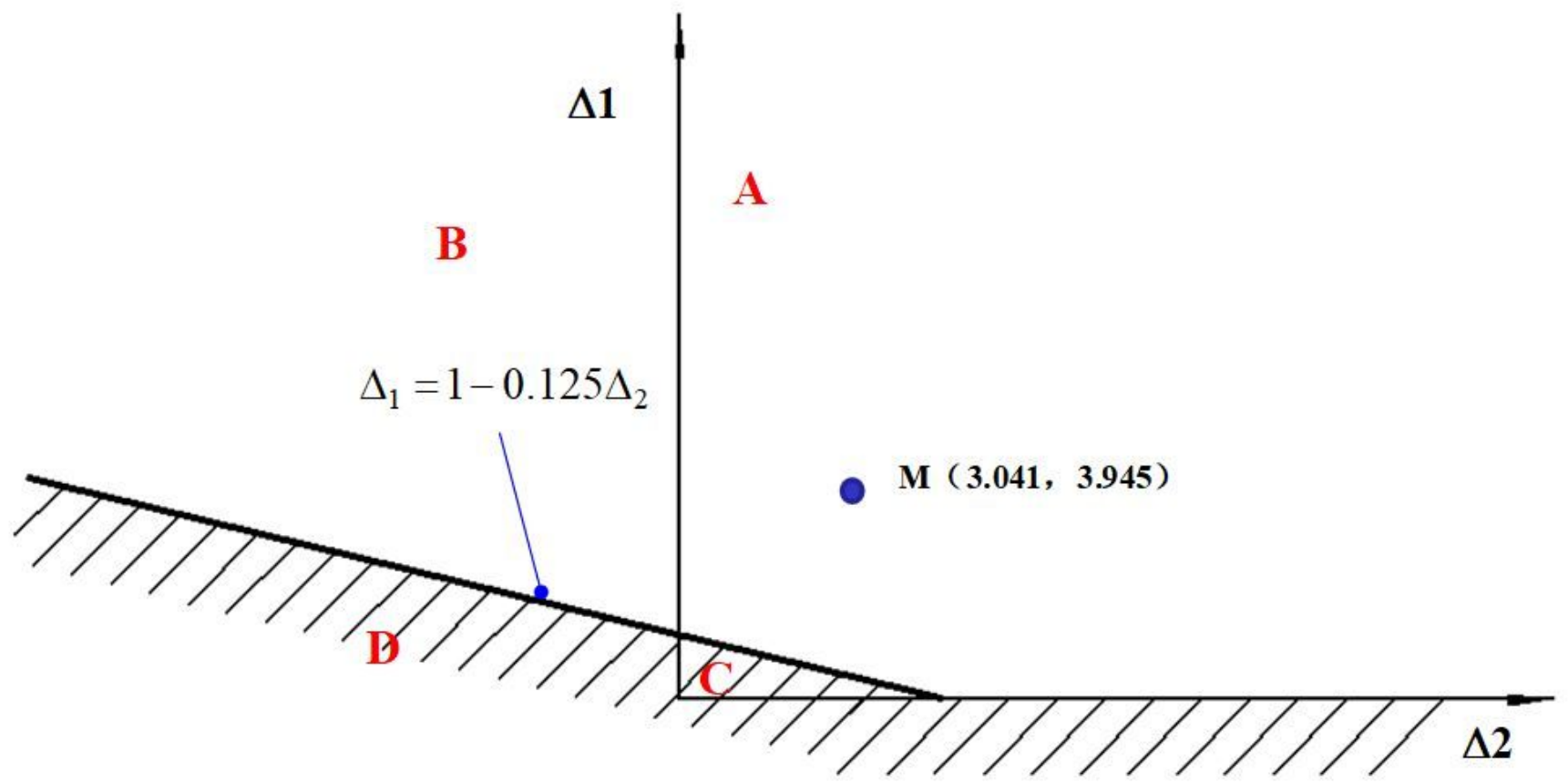

Figure 9

Schematic diagram of safe separation area for point $M$ 